\title{
Erratum
}

\section{Detection and Functional Analysis of Tumor Infiltrating T-Lymphocytes (TIL) in Liver Metastases from Colorectal Cancer}

\author{
Philipp Wagner, ${ }^{1}$ Moritz Koch, MD ${ }^{1}$ Daniel Nummer, PhD, ${ }^{2}$ Sylvia Palm, ${ }^{1}$ \\ Luis Galindo, MD, ${ }^{1}$ Daniel Autenrieth, ${ }^{1}$ Nuh Rahbari, MD, ${ }^{1}$ \\ Friedrich H. Schmitz-Winnenthal, MD, ${ }^{1}$ Volker Schirrmacher, PhD, ${ }^{2}$ \\ Markus W. Büchler, MD, ${ }^{1}$ Philipp Beckhove, $\mathrm{MD},{ }^{2}$ and Jürgen Weitz, $\mathrm{MD}^{1}$ \\ ${ }^{1}$ Department of Surgery, University of Heidelberg, INF 110, 69120 Heidelberg, Germany \\ ${ }^{2}$ Division of Cellular Immunology, Tumor Immunology Program, German Cancer Research Center, \\ INF 280, 69120 Heidelberg, Germany
}

Erratum to: $10.1245 / \mathrm{s} 10434-008-9971-5$

Annals of Surgical Oncology 15: 2310-2317

The author byline of the published article entitled, "Detection and Functional Analysis of Tumor Infiltrating T-Lymphocytes (TIL) in Liver Metastases from Colorectal Cancer" did not include author Nuh Rahbari, MD.

The correct author byline for this article is:

Philipp Wagner, Moritz Koch, Daniel Nummer, Sylvia Palm, Luis Galindo, Daniel Autenrieth, Nuh
Rahbari, Friedrich H. Schmitz-Winnenthal, Volker Schirrmacher, Markus W. Büchler, Philipp Beckhove and Jürgen Weitz.

This article was published online June 3, 2008 and published in the August 2008 print issue.

Published online February 7, 2009.

The online version of the original article can be found under doi: 10.1245/s10434-008-9971-5.

Address correspondence and reprint requests to: Jürgen Weitz, MD; E-mail: juergen.weitz@med.uni-heidelberg.de

Published by Springer Science+Business Media, LLC @ 2009 The Society of Surgical Oncology, Inc. 